\title{
AS DISPUTAS EM TORNO DE DIREITOS COMO UM PROCESSO EDUCATIVO: UM ESTUDO DE CASO SOBRE A OCUPAÇÃO "NOVO PINHEIRINHO" DE EMBU DAS ARTES, SP.
}

\author{
Renato Macedo de Almeida (mestrando Faculdade de Educação - USP); Profa. Kimi \\ Aparecida Tomizaki (Orientadora)
}

\section{RESUMO}

A presente pesquisa tem como objetivo central analisar os processos educativos envolvidos na luta por direitos sociais ou políticos, mais especificamente, os processos de socialização e formação relacionados ao engajamento político nas chamadas "causas coletivas. Tendo em vista analisar diferentes dimensões educativas, esta pesquisa assumirá como objeto de estudo a disputa entre o Movimento dos Trabalhadores SemTeto (MTST) e a Sociedade Ecológica Amigos de Embu (SEAE) em torno da Mata do Roque Valente, uma Área de Proteção Ambiental (APA) situada no município de Embu das Artes, São Paulo. Esse conflito que começou em 2012, tendo como foco a disputa em torno dos diferentes "usos" que poderiam ser feitos desse terreno, orientando a análise da investigação os documentas produzidos, observação de reuniões e atividades que ambos os grupos realizaram e, principalmente, pela reconstituição das trajetórias dos sujeitos da pesquisa (militantes dos dois movimentos citados) para a qual lançamos mão de entrevistas em profundidade, com ênfase sobre a "educação recebida" em diferentes instâncias anteriores à entrada no movimento e, posteriormente, nos processos de formação e ressocialização promovidos no interior dos dois movimentos em questão.

Palavras-chave: Socialização, militância, movimento ambientalista, movimento semteto.

\section{SOBRE OS DESAFIOS URBANOS E AMBIENTAIS NO BRASIL}

A análise dos conflitos envolvendo o Novo Pinheirinho, assim como uma imensa parcela dos conflitos relacionados ao território e seus diferentes usos, deve ser relativizada e avaliada frente aos processos que resultaram na urbanização dos grandes centros brasileiros.

Segundo Singer (1974) com a tardia industrialização nacional, iniciada fragilmente na década de 1930, ocorre a atração de trabalhadores rurais para as cidades, principalmente as Regiões Metropolitanas de São Paulo, Belo Horizonte, Porto Alegre, Curitiba e Rio de Janeiro. O aprofundamento do processo industrial brasileiro e a consequente mobilização de força de trabalho rural para as cidades teve como papel fundamental a formação de um "exército industrial de reserva, constituído pelas massas rurais submergidas numa economia de subsistência pré-capitalista". (Singer, 1973, p. $35)$.

Esta atratividade pode ser melhor expressa com os dados para as populações urbanas e rurais entre as décadas de 1940 e 2000. Em 1940, a população do campo era de 25 milhões enquanto a urbana somava cerca de 16 milhões, já para o ano de 2000, as 


\section{SEMINÁRIO DE PESQUISA EM CIÊNCIAS HUMANAS - SEPECH \\ Humanidades, Estado e desafios didático-científicos \\ Londrina, 27 a 29 de julho de 2016}

cidades brasileiras abrigavam 150 milhões de pessoas, enquanto o campo 24 milhões (Brito, 2006). Como consequência verificou-se o crescimento urbano desconcentrado, deixando vazios dentro da "mancha urbana" e o espraiamento da cidade para suas áreas mais periféricas e insalubres; alteração da paisagem com a retificação de rios para a construção de vias propícias aos veículos automotores; extensa diminuição da cobertura vegetal do território de diversos municípios que passaram por este processo e consequente queda na qualidade de seus recursos naturais. Logo, os municípios ao redor de São Paulo sofreram as consequências desse processo contínuo até os dias atuais.

Goulart (2011) ressalta que, durante esse processo, o grupo que mais sofreu foi a classe trabalhadora urbana, que antes residia nos cortiços e nas vilas operárias no início do século, sendo afastada para os morros e terrenos distantes dos equipamentos urbanos já estabelecidos no centro e, principalmente, da concentração dos empregos industriais. Nesse processo, foi negada aos trabalhadores a possibilidade da posse do imóvel, seja pela expulsão sazonal das áreas que se valorizavam pelo investimento público na cidade, seja pelo aumento dos preços dos imóveis para compra ou aluguel.

Inserida nesse contexto, Embu das Artes é denominada como uma instância turística, localizada na Sub-Região Oeste da Região Metropolitana de São Paulo (RMSP), totaliza 45 quilômetros de extensão em uma área total de aproximadamente 70 mil $\mathrm{km}^{2}$. Destes, $60 \%$ inserem-se em área de proteção aos mananciais, restando $40 \%$ deste total para a distribuição dos cerca de 261 mil moradores do município (IBGE, 2012) $)^{1}$.

Segundo o Plano Diretor Municipal de 2011, para a questão habitacional, Embu das Artes apresenta um déficit habitacional ${ }^{2}$ estimado em 8 mil famílias ${ }^{3}$. As ações que visam a regulação fundiária são muito restritas, muito por conta de Embu das Artes, como já foi dito anteriormente, ter $60 \%$ do seu território inserido em área de proteção aos mananciais. Em relação ao Índice de Áreas Verdes, valor obtido através do total de áreas verdes de um município em relação à sua população, Embu das Artes tem média de aproximadamente $182 \mathrm{~m}^{2} / \mathrm{hab}$., quando o recomendado pela Organização Mundial de Saúde é de $12 \mathrm{~m}^{2} / \mathrm{hab}$. Contudo o valor muito acima do recomendado não é proporcionalmente distribuído por suas regiões, sendo a Mata do Roque Valente localizada na Região Leste de Embu das Artes, área com a menor relação de cobertura vegetal por habitantes. ${ }^{4}$

\footnotetext{
${ }^{1}$ Disponível em: <

http://cidades.ibge.gov.br/xtras/temas.php?lang=\&codmun=351500\&idtema=130\&search=saopaulo|embu-das-artes|estimativa-da-populacao-2015->. Acesso em: jan. 2016

${ }^{2}$ Para déficit habitacional, o Plano Diretor de Embu das Artes de 2011 relaciona as habitações precárias, domicílios em situações inadequadas, coabitações familiares, pessoas em situação de rua e ônus excessivo com aluguel.

${ }^{3}$ Em 2001 esse número era de 6 mil.

${ }^{4}$ Revisão do Plano Diretor Participativo, continuação da 2a Audiência Pública Temática - Meio Ambiente Proposta Preliminar - Revisão 023 de março de 2011 Disponível em: <http://www.embudasartes.sp.gov.br/egov/public/arquivos/2011/03/plano_diretor_audiencia_meio_a mbiente_23032011.pdf>. Acesso em jan. 2016
} 


\section{SEMINÁRIO DE PESQUISA EM CIÊNCIAS HUMANAS - SEPECH \\ Humanidades, Estado e desafios didático-científicos \\ Londrina, 27 a 29 de julho de 2016}

\section{A MATA DO ROQUE VALENTE}

Nomeada como seu antigo proprietário era conhecido, a referida mata foi alvo de uma disputa judicial desde 1986, quando moradores da região reivindicavam junto ao poder público a sua utilização como Parque Ecológico, a fim de manter as características naturais do mesmo. Contudo, o terreno ficou sem uso, abandonado, o que mudou em 1988, ano em que ocorreu uma mobilização dos movimentos por direito à moradia pelo uso do terreno para a construção de moradia. Assim, a Companhia de Desenvolvimento Habitacional e Urbano do Estado de São Paulo (CDHU) adquiriu o terreno com projeto imobiliário e de Parque, (PMEA, 2013). Apesar disso, a área permaneceu abandonada, sendo a sua posse contestada judicialmente em 2006, por uma ação impetrada pela SEAE, que pedia que o terreno não fosse utilizado para o projeto habitacional, mas sim para a formalização apenas do parque.

Sabendo do impasse, o MTST organizou-se no início de 2012 para realizar a ocupação do assentamento que se tornou conhecido como "Novo Pinheirinho", forçando alguma tomada de decisão. Disso surgiu o embate entre as duas organizações, culminando em uma ação judicial de desocupação da mata, impetrada junto à justiça pela SEAE e prontamente acatada. Isso acirrou os ânimos entre ambos os movimentos, visto que a análise da ocupação pelo técnico da justiça não foi efetivada, tendo o responsável alegado falta de segurança para fazê-lo - ainda que não houvesse ocorrido alguma tentativa com escolta policial ou algo semelhante ${ }^{5}$.

Após muitas manifestações e decisões judiciais pouco favoráveis, ainda com o terreno ocupado, o MTST realizou em julho de 2013 a interdição ${ }^{6}$ da Rodovia Régis Bittencourt, que liga o município de São Paulo à Região Sul, tendo representantes recebidos pelo governador do estado de São Paulo, Geraldo Alckmin, e sua equipe. O resultado, até certo ponto surpreendente, foi o compromisso do governo estadual de destinar a área à construção de moradias populares, seguindo o projeto já elaborado pela CDHU, tendo o MTST se comprometido a desocupar pacificamente o terreno.

Como consequência direta dessa negociação, em 2013 ocorreu a eleição para o conselho gestor da APA, responsável por discutir e deliberar as ações para a área. Já em fevereiro de 2014, os governos do município e do estado anunciaram o fim da disputa judicial, permitindo, assim, a execução das obras necessárias para a instalação dos equipamentos previstos ${ }^{7}$.

\section{O MOVIMENTO DOS TRABALHADORES SEM-TETO (MTST)}

O MTST é uma organização relativamente recente, formada em 1997, de certa maneira distante do surgimento dos primeiros movimentos por moradia no Brasil, que datam dos anos 1960 e foram fortemente relacionados com a ação dos movimentos eclesiásticos de base e a doutrina da teologia da libertação, portanto, ligados a

${ }^{5}$ Disponível em: <http://criticadodireito.blogspot.com.br/2012/05/escandaloso-juiza-de-embuaplica-multa.html>. Acesso em: jan. 2016.

6 Disponível em: <http://agenciabrasil.ebc.com.br/geral/noticia/2014-01/mtst-e-recebido-porgovernador-de-sp-e-tem-pautas-atendidas>. Acesso em: jan. 2016.

7 Disponível em: <http://www.cmembu.sp.gov.br/noticias/1322/area-da-mata-do-roque-valente-eliberada-para-a-construcao-de-moradias>. Acesso em: jan. 2016. 


\section{SEMINÁRIO DE PESQUISA EM CIÊNCIAS HUMANAS - SEPECH \\ Humanidades, Estado e desafios didático-científicos \\ Londrina, 27 a 29 de julho de 2016}

determinados setores da Igreja Católica. Esses movimentos, surgidos na década de 1960, organizaram diferentes demandas fundiárias em torno da União dos Movimentos de Moradia (UMM), e outras, como o Movimento dos Trabalhadores Rurais Sem Terra (MST), que posteriormente seria uma organização de referência para a criação do MTST (Goulart, 2001).

A estratégia central do MST é o uso das denominadas "ocupações" em terrenos periféricos $^{8}$, ações geralmente chamadas de "invasões" por algumas instâncias legais. Isso coloca em evidência uma "disputa simbólica desses movimentos pela nomeação da ação, confrontando os limites do direito à propriedade privada" e ilustrando o cenário de litígio até de convicções ideológicas (Miagusko, 2008, p. 58).

A ocupação dos terrenos visa o atendimento das necessidades habitacionais nas grandes cidades, auxiliando na conquista de cidadania de seus integrantes, na forma de moradia. Contudo, segundo Boulos (2012), suas pretensões não se esgotam na questão habitacional ou por melhorias na qualidade dos serviços e infraestrutura urbana. A pretensão do MTST é a de organizar os trabalhadores que vivem nas regiões periféricas dos grandes centros brasileiros ${ }^{9}$ em uma luta que questiona o papel do Estado na garantia de direitos, visto que há uma compreensão de que o Estado apenas confirma as desigualdades existentes, favorecendo o poder do capital nas decisões do que é público.

\section{A SOCIEDADE ECOLÓGICA AMIGOS DE EMBU - SEAE}

A SEAE surgiu em meados da década de 1970 com a intenção inicial de impedir a construção de um aeroporto na região de Caucaia, Cotia. A ONG atua em diversas atividades no município de Embu das Artes tanto na área ambiental, geralmente procurando sensibilizar a população para temas diversos com atividades artísticas, torneios de futebol, trilhas ecológicas, apresentações teatrais e shows musicais, como em programas de educação digital e capacitação profissional de jovens e adultos. Assim, a entidade, que assume o papel de representação das demandas ambientais de Embu das Artes, protagonizou um dos lados da disputa em torno dos possíveis usos da região da Mata do Roque Valente, tendo em vista torná-la uma área de proteção em toda sua extensão, nunca admitindo qualquer possibilidade de destinar o espaço a usos compartilhados, como foi proposto tanto pelo MTST, quanto pelo projeto da CDHU.

Ainda a respeito de sua relação com a sociedade civil organizada de Embu, a SEAE relata em sua página na Internet o apoio nas ações propostas pela Comissão do

\footnotetext{
8 "A opção de atuar nas periferias é motivada por não ser um movimento de moradia; nos centros, as ocupações estariam isoladas, em um meio hostil. No centro seria um combate à gentrificação, uma ocupação de resistência à lógica mercadológica, mas não se irradiaria, sendo os centros o local do comércio, capital etc. Já nas periferias você consegue acumular força e trabalho de base para além da ocupação, pois os bairros do entorno são a mesma base social dentro da perspectiva de acumulo de forças." (José, 34 anos, coordenador nacional do MTST em entrevista realizada em 15 dez. 2013.)

${ }^{9}$ Documento produzido no I Encontro Nacional Movimento dos Trabalhadores Sem-Teto: As linhas políticas do MTST, 2001. Disponível em: < file://C:/Users/Renato/Downloads/16761-52551-1PB.pdf>. Acesso em: jan. 2016.
} 


\section{SEMINÁRIO DE PESQUISA EM CIÊNCIAS HUMANAS - SEPECH \\ Humanidades, Estado e desafios didático-científicos \\ Londrina, 27 a 29 de julho de 2016}

Movimento Pró-Parque Pirajuçara, criado pela própria ONG com o suporte de diferentes órgãos públicos e privados de representação da sociedade, garantindo uma rede de relações que auxilia nas atividades da organização

\section{O CONCEITO DE SOCIALIZAÇÃO COMO INSTRUMENTAL ANALÍTICO}

Sendo esta pesquisa construída pela relação existente entre os desafios urbanos e a preservação do meio ambiente, e focada, principalmente, nas experiências educativas de indivíduos engajados em movimentos coletivos que discordam entre si em relação a esses desafios, é fundamental considerar a situação social de indivíduos e grupos envolvidos e suas diferentes modalidades de socialização, visto que partimos da hipótese de que as visões de mundo dos militantes dos dois movimentos em questão se diferenciam em função dos "lugares sociais" ocupados por eles ao longo de sua formação. Conforme Setton (2009), essa análise deve identificar a:

[...] variação da força dos recursos que cada agente ou instituição acumula ao longo de uma trajetória. Socializados e socializadores, no espaço de luta simbólica de socialização, tem poderes, todavia, certamente diferenciados entre si. Assim, debruçar-se sobre as articulações entre as agências socializadoras a partir da ótica relacional com o indivíduo é um convite para o entendimento da constituição dos poderes e domínios, a luta e a indissociabilidade simbólica entre indivíduos e sociedade (p.721)

Para esta análise, a obra de Pierre Bourdieu será de fundamental importância, uma vez que sua noção ou conceito de habitus $^{10}$ é de grande valia para a apreensão e análise das relações de afinidade entre o comportamento dos agentes e as estruturas e condicionamentos sociais (Setton, 2002). Compreender as origens do habitus dos militantes envolve, portanto, a pesquisa das histórias de vida de representantes de cada grupo, sua trajetória ${ }^{11}$, a fim de apreender a coletividade de que seu informante faz parte, e como o encara, registrando a experiência de diversos indivíduos de uma mesma coletividade, convergindo relatos de um período de tempo (Queiroz, 1987). Essa opção, além de considerar o indivíduo como um fenômeno social, pretende captar "aspectos importantes de sua sociedade e do seu grupo, comportamentos e técnicas, valores e ideologias que podem ser apanhadas através de sua história." (QUEIROZ, 1987, p. 14). Para a análise são consideradas também as instâncias educativas não formais, como bem destacam Kowarick e Bonduki (1986 apud Goulart, 2011, p. 103):

${ }^{10}$ Bourdieu preconiza que o habitus seria como um sistema de disposições adquiridas pela incorporação de "estruturas estruturantes", formando um corpo estruturado que incorporou as estruturas imanentes de um mundo - ou de um setor particular desse mundo, de um campo -, estruturando assim a percepção que se tem desse mundo e a sua ação nele (Bourdieu, 1996).

11 “[...] para Bourdieu, o conceito de 'trajetória' implicaria objetivar as relações entre os agentes, sem deixar de lado suas forças em campo. Dessa maneira [...] a trajetória procuraria descrever posições simultaneamente ocupadas em sucessivos campos de força: tanto individuais como 'em relação' a demais grupos sociais em concorrência." (Schwarcz, 2013, p. 58). 


\section{SEMINÁRIO DE PESQUISA EM CIÊNCIAS HUMANAS - SEPECH \\ Humanidades, Estado e desafios didático-científicos \\ Londrina, 27 a 29 de julho de 2016}

[...] reivindicações de bens coletivos "politizam" os moradores atuantes nesses movimentos, forjando grupos e associações, em um processo de "consciência da exclusão" que abre campo de resistência ao caráter autoritário do regime e amplia a organização popular [...]

Conforme Sawicki e Siméant (2011), é particularmente interessante comparar os modos de recrutamento, composição e manutenção do engajamento de organizações militantes com modalidades de institucionalização bastante diferentes. Usar $\mathrm{o}$ instrumental teórico brevemente apresentado acima poderá contribuir para a discussão que se pretende realizar.

\section{AS ENTREVISTAS}

Abaixo, o quadro resumido dos entrevistados, seguido por uma descrição de eventos relatados pelos mesmos, segundo as diferentes instancias de socialização:

\begin{tabular}{|c|c|c|c|c|c|c|}
\hline Nome & $\begin{array}{l}\text { Tempo de } \\
\text { militância }\end{array}$ & Idade & $\begin{array}{l}\text { Atividade } \\
\text { profissional }\end{array}$ & $\begin{array}{l}\text { Orige } \\
\text { m }\end{array}$ & Escolaridade & $\begin{array}{l}\text { Escolaridad } \\
\text { e (pais) }\end{array}$ \\
\hline Amanda & $\begin{array}{l}\text { MTST }-4 \\
\text { anos }\end{array}$ & 41 & Desempregada & SP & E. Médio & $\begin{array}{l}\text { F. I } \\
\text { Incompleto } \\
\text { ambos }\end{array}$ \\
\hline Romário & $\begin{array}{l}\text { MTST - } 11 \\
\text { anos }\end{array}$ & 46 & $\begin{array}{l}\text { Secretaria } \\
\text { MTST }\end{array}$ & SP & E. Médio & $\begin{array}{l}\text { F. I } \\
\text { Incompleto } \\
\text { ambos }\end{array}$ \\
\hline Gustavo & $\begin{array}{l}\text { SEAE }-13 \\
\text { anos }\end{array}$ & 57 & $\begin{array}{l}\text { Analista } \\
\text { sistemas }\end{array}$ & SP & $\begin{array}{l}\text { Superior } \\
\text { engenharia } \\
\text { (especialização } \\
\text { MBA) }\end{array}$ & Sup. ambos \\
\hline Sandra & $\begin{array}{l}\text { SEAE }-10 \\
\text { anos }\end{array}$ & 49 & Jornalista & SP & $\begin{array}{l}\text { Superior } \\
\text { jornalismo } \\
\text { (especialização } \\
\text { pós-graduação) }\end{array}$ & Sup. Ambos \\
\hline
\end{tabular}

\section{A INFÂNCIA}

O período da infância e suas vivências são de grande influência para a explicar o processo de socialização, também sendo marcante para todos os entrevistados, mesmo que de formas diferentes. Para os dois representantes do SEAE, este foi um período relatado de muitas descobertas relacionadas à natureza, às brincadeiras ao ar livre de Gustavo em Campinas e de Sandra, em Embu das Artes. Contudo, para Amanda, do MTST, as lembranças são de muitas dificuldades. Além de se recordar do pouco dinheiro disponível na ocasião, ela aponta o fato da ausência da mãe, ocupada como empregada doméstica e a ausência do pai, que abandonou a família quando ela tinha dois anos de idade, para sua percepção negativa do período. Romário, ainda que tenha crescido em um bairro simples, na Zona Leste de São Paulo, parece ser 


\section{SEMINÁRIO DE PESQUISA EM CIÊNCIAS HUMANAS - SEPECH \\ Humanidades, Estado e desafios didático-científicos \\ Londrina, 27 a 29 de julho de 2016}

recompensado com as recordações das transformações acompanhadas nas ruas de Ermelino Matarazzo e das brincadeiras e estripulias feitas, como nadar no Tietê, já, na época pouco indicado devido à alta concentração de poluentes.

Vale ressaltar que algumas das lembranças descritas pelos integrantes do SEAE são relacionadas ao convívio com o meio ambiente e com ensinamentos que seus pais ou avós lhes deram com pequenos gestos. Exemplifica-se isto quando Sandra ressalta a frequência com que suas brincadeiras se relacionavam à natureza, ou em acompanhar a mãe em tarefas culinárias. Ou ainda no relato de como Gustavo aprendeu a transferir uma muda de Salvia sp. do terreno, vivências certamente marcantes para ambos. Para Romário o que parece ter relevância no período é a descoberta das amizades e as aventuras praticadas, inclusive a que se refere à interdição do tráfego de ônibus, feita por ele e por amigos em um protesto em seu bairro.

\section{ESCOLARIDADE DOS PAIS E AVÓS}

Considerar a formação educacional e profissional dos avós e pais dos entrevistados, significa, observar a possível influência que isto pode ter sobre eles, como no seu sucesso escolar, suas possibilidades de futuro e possíveis aspirações profissionais.

Os avós dos entrevistados do MTST não possuíam estudo algum, além de serem de origem humilde e originários de estados do Nordeste do país. Além dos avós, os pais de ambos não completaram os estudos, apenas o pai de Amanda, cujo Ensino Fundamental I foi finalizado. Os avós dos entrevistados da SEAE eram todos imigrantes estrangeiros, Gustavo recorda-se que o avô materno era norte-americano, sendo o primeiro médico homeopata e quiroprata da América do Sul, enquanto sua avó lecionava língua inglesa. Sandra não sabe ao certo a formação escolar dos avós, porém acha que que a avó paterna possuía o Ensino Médio completo, enquanto o avô materno era mestre de obras.

$\mathrm{Na}$ questão profissional de seus pais, outro aspecto em comum aos membros da SEAE se refere à alta escolarização de suas profissões, pais médicos, mães professora e revisora de texto. O oposto é verificado na profissionalização dos pais de Romário, agricultores e de Amanda, cuja mãe é empregada doméstica.

\section{ESCOLARIZAÇÃO}

A escola possuiu diferentes significados para os participantes da pesquisa, para os entrevistados do MTST, esse foi um período de discussões e aprendizados mais relacionados à reflexão política, do que para a profissionalização. Para Amanda, as lembranças positivas se referem à professores marcantes e a empolgação que as disciplinas da área de Humanas lhe despertavam. Para Romário, ficaram marcadas a diferença do nível de ensino encontrado em Pernambuco, as experiências dele próprio lecionando, mesmo com o Ensino Médio incompleto. Mesmo que tenham completado os estudos, em escola pública, o ensino médio foi o limiar de suas trajetórias nos estudos formais. A aprovação nos vestibulares que prestaram para Fatec e USP não foram garantia de continuidade para ambos entrevistados do MTST. Quando 


\section{SEMINÁRIO DE PESQUISA EM CIÊNCIAS HUMANAS - SEPECH \\ Humanidades, Estado e desafios didático-científicos \\ Londrina, 27 a 29 de julho de 2016}

questionados se foram pressionados por seus pais por esta desistência, nenhum deles mencionou essa preocupação.

Para Gustavo, os estudos sempre foram prioridade. Aprendeu inglês com desenvoltura ainda jovem, posteriormente formou-se em um colégio técnico, onde, adiante lecionou devido a sua formação em engenharia na Unicamp, instituição que também aprendeu alemão e francês, junto da à graduação. Já adulto, não concluiu o mestrado por questões relacionadas ao casamento, se especializando na Alemanha e concluindo um MBA nos Estados Unidos. Sandra também teve a educação como prioridade em sua formação. Desde o ensino infantil, feito em um ambiente residencial, passando pela formação sem reprovações nos ensinos fundamental e médio, a boa recordação da escola pública que frequentou em Embu das Artes, além do ensino técnico em secretariado, culminando em duas graduações, pós-graduações e especializações em diferentes áreas, todas em instituições particulares.

\section{ESTÍMULOS AO ESTUDO}

A influência dos pais de Sandra, envolvida na SEAE e ex-assessora de comunicação da entidade, não foram realizados de forma direta, mas através dos exemplos. O pai, ambientalista e um dos fundadores da SEAE, a mãe, dona de casa "exemplar", profissional de letras, revisora de textos e professora. Mesmo ela dando os créditos ao seu sucesso escolar ao seu esforço, não é de se desconsiderar sua trajetória e a de seus pais. A religião seguida pelos pais, alicerçada na obra "Na Luz da Verdade" de Abdruschin, parece ser um ponto muito importante nessa relação entre os pais e a entrevistada. Gustavo talvez tenha o relato em que a presença dos pais em sua formação se torna mais determinante no sucesso escolar desfrutado. Alfabetizado quando criança no inglês por ambos, o estímulo à leitura com o acesso a revistas de divulgação científica e a importância em frequentar as melhores escolas retratam essa sensação. Suas opiniões refletem o peso que destina à importância dos estudos e à formação política, atribuída inclusive, às histórias de seu pai.

Amanda confere o seu desempenho escolar ao seu próprio esforço, a mãe semialfabetizada e ocupada com o emprego e mais quatro filhos teve maior ascendência sobre Amanda quando esta optou pelo catolicismo na adolescência, crença logo substituída pelo ateísmo. $\mathrm{O}$ fato dela não se matricular no curso superior devido às baladas, mostra um pouco sobre a sua independência e a pouca ingerência da mãe nas suas escolhas. O outro militante do MTST recorda-se da importância que a mãe dera aos seus estudos, como toda mãe nordestina, segundo ele. O pai não se envolvia nestas questões. A mãe também parece ter tido alguma interferência em sua militância pelo PT. Suas recordações acerca do caso em que a acompanha em uma eleição para que ela não se enganasse na hora do voto, é um exemplo.

\section{EXPERIÊNCIAS PROFISSIONAIS}

A história profissional dos entrevistados do MTST é tremendamente distinta daquela relatada pelos entrevistados da SEAE. Os primeiros trabalham desde aproximadamente a puberdade, ainda em idade escolar, conjugando a escola e a 


\section{SEMINÁRIO DE PESQUISA EM CIÊNCIAS HUMANAS - SEPECH \\ Humanidades, Estado e desafios didático-científicos \\ Londrina, 27 a 29 de julho de 2016}

necessidade de ganhar dinheiro. Em situação de maior precariedade, Amanda realizou bicos diversos, inclusive vendedora de jazigos e catadora de latas. Romário trabalha também desde muito cedo em atividades muito distintas, como mecânico, balconista, professor, secretário da Apeoesp e atualmente, do MTST.

A história profissional de Sandra é iniciada quando estava no primeiro ano da faculdade, como uma forma de se tornar independente financeiramente. Prosseguiu os seus estudos, tornando-se educadora ambiental e, posteriormente, prestando serviços de assessoria de imprensa para a SEAE. Gustavo começou a trabalhar no ensino técnico, depois de graduar-se começa a lecionar no colégio que estudara, prosseguindo sua carreira de analista de sistemas.

\section{RAZÕES PARA A MILITÂNCIA}

A tarefa de encontrar motivações para o engajamento é, talvez, a conclusão mais complicada de se realizar, uma vez que os eventos da vida podem ser multifatoriais, influenciados por experiências muitas vezes aleatórias. Contudo, os depoimentos dados permitem algumas propostas para essa análise.

Desde pequenos, Sandra e Gustavo foram incutidos com ideais que valorizam a preservação valorização do meio ambiente e o convívio com a natureza. Ambos residem em Embu das Artes há muitos anos, possuindo forte relação com a SEAE. O pai de Sandra fundou a ONG, assim como o pai da ex-esposa de Gustavo. Ambos possuem forte relação com a Ordem do Graal na Terra, religião com sede em Embu, além de Gustavo citar alguns personagens importantes de Embu das Artes e do ambientalismo brasileiro, como Paulo Nogueira Neto, Mario Mantovani e Marcos Sorrentino, como sendo parte atuante da SEAE na sua entrada no movimento. Sandra formaliza sua entrada após a participação de uma oficina. Nela, começa a fazer o trabalho de comunicação da entidade.

Em relação aos militantes do MTST, sua aderência à causa nos parece ter uma forte influência da realidade vivida ao longo de suas vidas. Bairros precários, inconformismo com algumas situações enfrentadas, como: dificuldades financeiras, violência policial, poucas possibilidades de trabalho e de inserção na pauta política são alguns exemplos. Nesse sentido, a atuação das amizades de bairro e professores no processo de reflexão política podem ter aprofundado suas predisposições. Não é de se ignorar o impacto que Lula teve em ambas trajetórias militantes, tanto em seus engajamentos na campanha de 1989, quanto os períodos de governo Lula.

\section{CONQUISTAS OBTIDAS}

Os ganhos obtidos com a militância parece ser uma unanimidade nos relatos. Ainda que citem dificuldades dessa opção, como o não reconhecimento pelas conquistas e impossibilidade de se dedicar exclusivamente à causa, como cita Gustavo, os resultados são comemorados. Para Romário, a busca por soluções de problemas que não são da responsabilidade do MTST, nem de resolução fácil são comuns, mas não desanimam seus engajamentos. Contudo, o empoderamento conquistado pelos militantes do MTST são os ganhos mais facilmente percebidos nas entrevistas. Ter um 


\section{SEMINÁRIO DE PESQUISA EM CIÊNCIAS HUMANAS - SEPECH \\ Humanidades, Estado e desafios didático-científicos \\ Londrina, 27 a 29 de julho de 2016}

direito atendido, conseguir negociá-los, resolver situações de conflito iminente e ainda obter visibilidade para suas causas, são, ao final desta etapa de coleta de dados, o que faz com que alguns de seus militantes permaneçam atuantes, mesmo que tenham conseguido o seu lar.

\section{APRENDIZADO NO INTERIOR DOS MOVIMENTOS}

O processo de aprendizado feito pelos dois grupos difere substancialmente. $\mathrm{O}$ SEAE ocupa-se de um setor da educação que prioriza a formação técnica e capacita jovens e adultos em cursos técnicos e palestras de educação ambiental, não existindo um processo para a formação de uma militância atuante, existindo algumas pessoas mais assíduas e muitos simpatizantes do SEAE, não se refletindo em ações com forte apoio popular.

O MTST se preocupa em realizar eventos de formação política para coordenadores de ocupações, palestras para seus militantes antes de atos e a distribuição de cartilhas. Contudo, como o relatado para a entrada no movimento, o empoderamento dos militantes em terem alguns de seus anseios atendidos, age como um forte caráter educativo, uma vez que eles próprios enxergam resultados nos seus êxitos.

\section{CONSIDERAÇÕES FINAIS}

A composição de um quadro mais extenso e, se possível, variado de representantes da SEAE e do MTST, contribuirá na validação dos dados, que, em um primeiro momento já nos fornece muitas informações sobre quem são, como se enxergam nos movimentos e, quais fatores podem os ter levado às escolhas feitas em suas trajetórias militantes.

O conflito deflagrado com a ação do MTST na ocupação da Mata do Roque Valente, com posterior ação judicial impetrada pela SEAE, revelou alguns aspectos interessantes para a discussão dos capitais que cada um deles exerceu ao longo do processo. As redes estabelecidas com diferentes personalidades da cidade e da política, explicitam a importância do capital social na tentativa de desfecho da situação. Este exercício de poder foi praticado, assim como na tentativa de desqualifica-los mutuamente, seja desmerecendo a pouca formação educacional de uns, seja desdenhando da condição socioeconômica privilegiada de outros.

Mesmo que o objetivo central não tenha sido avaliar estas relações, creio que será de grande valia este exercício, somado ao aprofundamento teórico necessário sobre o processo de socialização para a conclusão deste trabalho.

\section{PRINCÍPIOS ÉTICOS}

Esta pesquisa reconhece o Código de Ética proposto pela Universidade de São Paulo e seguirá os princípios estabelecidos na Resolução CNS 466/2012. 


\section{SEMINÁRIO DE PESQUISA EM CIÊNCIAS HUMANAS - SEPECH \\ Humanidades, Estado e desafios didático-científicos \\ Londrina, 27 a 29 de julho de 2016}

\section{REFERÊNCIAS}

ACSELRAD, H. Meio ambiente e democracia. Rio de Janeiro: Ibase, 1992. BOULOS, G. Por que ocupamos? Uma introdução à luta dos sem-teto. São Paulo: Scortecci, 2012.

BOURDIEU, P. Questões de sociologia. Rio de Janeiro: Marco Zero, 1983.

. A distinção: crítica social do julgamento. São Paulo: Edusp, 2007.

. Razões práticas. São Paulo: Papirus, 2014.

BRITO, F. O deslocamento da população brasileira para as metrópoles. Estudos avançados, São Paulo, v. 20, n. 57, Ago. 2006. Disponível em:

$<$ http://www.scielo.br/scielo.php?script=sci_arttext\&pid=S0103-

40142006000200017\&lng=en\&nrm=iso>. Acesso em: jul. 2014.

GOUlART, D. C. O anticapitalismo do Movimento dos Trabalhadores Sem-Teto (MTST). Tese de doutorado - Universidade Estadual Paulista, Faculdade de Filosofia e Ciências, Marília, 2011.

MARTINS, G. P. C \& AMARAL, M. C. M. O habitus em Bourdieu e a teoria da justificação de Boltanski e Thévenot. Latitude, vol. 3, n. 2, pp. 96 - 108, 2009.

MIAGUSKO, E. Movimentos de moradia e sem-teto em São Paulo: experiências no contexto do desmanche. Tese de Doutorado, Sociologia - Universidade de São Paulo, São Paulo, 2008.

QUEIROZ, M. I. P. Relatos Orais: do "indizível" ao "dizível”. In: VON SIMSON, O. M. (Org.) Exerimentos com histórias de vida (Itália-Brasil). São Paulo: Vértice, 1998. P. 15-43.

SAWICKI, F.; SIMÉANT, J. Inventário da sociologia do engajamento militante: nota crítica sobre algumas tendências recentes dos trabalhos franceses. Sociologias, Porto Alegre, ano 13, n. 28, p. $200-255$, set./dez. 2011.

SCHWARCZ. L. M. Biografia como gênero e problema. História social, n. 24, pp. 51 $-72,2013$.

SETTON, M. G. A teoria do habitus em Pierre Bourdieu: uma leitura contemporânea. Revista Brasileira de Educação, n. 20, p. 60-70, 2002.

A socialização como fato social total: notas introdutórias sobre a teoria do habitus. Revista Brasileira de Educação. Rio de Janeiro, v. 14, n. 41, ago. 2009. Disponível em: $\quad<$ http://www.scielo.br/scielo.php?script $=$ sci_arttext\&pid=S1413$24782009000200008 \& \operatorname{lng}=$ en\&nrm=iso $>$. Acesso em: jul. 2014. 


\section{SEMINÁRIO DE PESQUISA EM CIÊNCIAS HUMANAS - SEPECH \\ Humanidades, Estado e desafios didático-científicos \\ Londrina, 27 a 29 de julho de 2016}

Teorias da socialização: um estudo sobre as relações entre indivíduos e sociedade. Educação e Pesquisa, São Paulo, v.37, n.4, p.711 - 724, dez. 2011.

SINGER, P. Urbanização e desenvolvimento: o caso de São Paulo. In: SINGER, Paul. (Org.) Economia política da urbanização. 13. ed. São Paulo: Brasiliense. p. 117-133, 1973. 